\title{
First results on growth and cropping of pear trees budded at different heights
}

\author{
A. Blanco \\ CENIA de Aula Dei \\ Apartado 727 \\ 50080 - ZARAGOZA \\ SPAIN
}

\begin{abstract}
Pear trees cv 'Agua de Aranjuez' A-840 (VT) clon, budded in the nursery at 15 and $50 \mathrm{~cm}$ from the soil were planted with the union at 10 and $50 \mathrm{~cm}$ high, and growth and cropping during the first two years recorded. Scion trunk-cross- sectional area was smaller on the high-worked trees from the time of planting, and stock area at soil level was also smaller on the high-budded trees from the first year after planting. Almost all the high-worked trees carried a crop on the second year of growth, while a few (20\%) of the low-budded carried some fruits, which were smaller in size. Differences in size of both scion and stock were greater by the end of the second year.
\end{abstract}

\section{1 - Introduction}

'Agua de Aranjuez' is a very vigorous pear variety (P y r u s c o m m u n i s L.) usually grown in Spain on pear seedling rootstocks, for wich the adult tree attains a very large size. The need for a growth control has led to the use of quince rootstocks, and first reports are showing that 'Agua de Aranjuez' A-840 (VT) clon grafted on Quince C (EM) results in a tree of small size and early cropping, but which needs staking because of poor anchorage and twisting down of the aerial part of the stock.

Van Oosten (1978) and Parry (1986) have shown that in apple, high working increases the dwarfing effect of the rootstock, allowing the use of more vigorous rootstocks. To test this effect on pear trees, a preliminary trial has been carried out and the results on growth and cropping during the first two years after planting are presented here.

\section{2 - Materials and Methods}

Quince A rootstocks were grafted in the nursery in 1981 at two different heights: 15 and $50 \mathrm{~cm}$ from the ground with 'Agua de Aranjuez'A-840 buds. Ten trees of each height of budding were chosen as uniform as possible and of the best quality, in terms of tree height and number of feathers. The trees were planted in a row at $3.5 \mathrm{~m}$ apart, 
placing one high worked tree followed by a low budded one, in a pear orchard of the SIA farm in Zaragoza, on December 1982. The unions remained at 10 and $50 \mathrm{~cm}$ high from the soil after planting. The trees were pruned to a center leader shape, for which all feathers that had grown at a height of less than $60 \mathrm{~cm}$ were removed after planting.

Rootstock and scion girths were respectively measured at soil level and $12 \mathrm{~cm}$ above the union, from the winter of 1982-83 onwards, and records on the number of flower buds and cropping were taken during 1984.

\section{3 - Results}

The trees showed certain differences at planting. The scion size, measured by the trunk-cross-sectional area, in the high worked trees was significantly smaller $(P \leq 0.01)$ than in those budded low, but the rootstock trunk-cross-sectional area was similar in both types of trees. Besides, most of the trees had feathers in the lower part of the scion stem, which were removed in the low-budded trees because of being too low to use them as primary branches, while most of them were left on the high-budded trees.

By the end of the first growing season, the differences in size of the scion were more evident $(\mathrm{P} \leq 0.001)$, and also a greater growth of the stock in the low-budded trees was recorded $(\mathrm{P} \leq 0.001)$ (Figure 1$)$.

In the following spring, flower buds were observed on a certain number of trees: 80 per cent of the high worked trees carried flower buds, while these appeared in only 20 per cent of the low budded ones. This led to differences in the cropping behaviour of the two types of trees (Table 1). The high budded trees carried a certain crop while the lowbudded ones beared a negligible yield both when considering the total tree number or only the cropping trees. Fruits were greater in size in the high-worked trees. By the end of the growing season the differences in scion and stock size, were even more evident $(\mathrm{P} \leq 0.001)$ (Figure 1).

\section{4 - Discussion}

These preliminary results indicate that growth and cropping of pear trees budded at different heights are different in the first years of the orchard life. High-working has increased the dwarfing effect induced by Quince A when budded low, as has been pointed out in apple (van Oosten, 1978; Parry, 1986). Besides, an effect of the scion on rootstock growth has also been observed as the trunk area at soil level was greater on the stocks budded at $10 \mathrm{~cm}$ than on the high-worked trees. The high-budded trees have shown to start cropping on the second year, mainly because feathers were left on the trees, which carried on the following year most of the flower buds and consequently producing the first fruits. Fruits were slightly greater in the high-worked trees than in those budded low. 
However, Parry (1986) points out that differences in growth and cropping may finally decrease as the trees become older, specially when grown on the more envigorating rootstocks, for which long-term trials to test the behaviour of high-worked 'Agua de Aranjuez' on Quince A trees during the whole orchard life are necessary.

\section{5 - -References}

van OOSTEN, H.J., 1978. High working for control of vigor of apple trees. Acta Horticulturae, 65:157-166

PARRY, M.S., 1986. The effect of budding height on the field performance of two apple cultivars on three rootstocks, Journal of Horticultural Science, 61:1-7.

Table 1.- Flower bud number and crop load of trees budded at different heights, on their second leaf ('Agua de Aranjuez' / Quince A)

\begin{tabular}{lcc}
\hline Height of union & $50 \mathrm{~cm}$ & $10 \mathrm{~cm}$ \\
\hline $\mathrm{N}^{\mathrm{o}}$. of flower-buds per tree & $13.5 \pm 3.5$ & $0.5 \pm 0.4$ \\
Proportion of cropping trees $(\%)$ & 80 & 20 \\
Yield per tree $(\mathrm{Kg})$ & $1.97 \pm 0.57$ & $0.06 \pm 0.04$ \\
Yield per cropping tree $(\mathrm{Kg})$ & $2.46 \pm 0.59$ & $0.31 \pm 0.02$ \\
$\mathrm{~N}^{\mathrm{o}}$. of fruits per tree & $14.1 \pm 4.7$ & $0.5 \pm 0.3$ \\
$\mathrm{~N}^{\mathrm{o}}$. of fruits per cropping tree & $17.6 \pm 5.1$ & $2.5 \pm 0.5$ \\
Mean fruit weight $(\mathrm{g})$ & $147.5 \pm 13.5$ & $125.8 \pm 19.2$ \\
\hline
\end{tabular}

Mean \pm standard error 

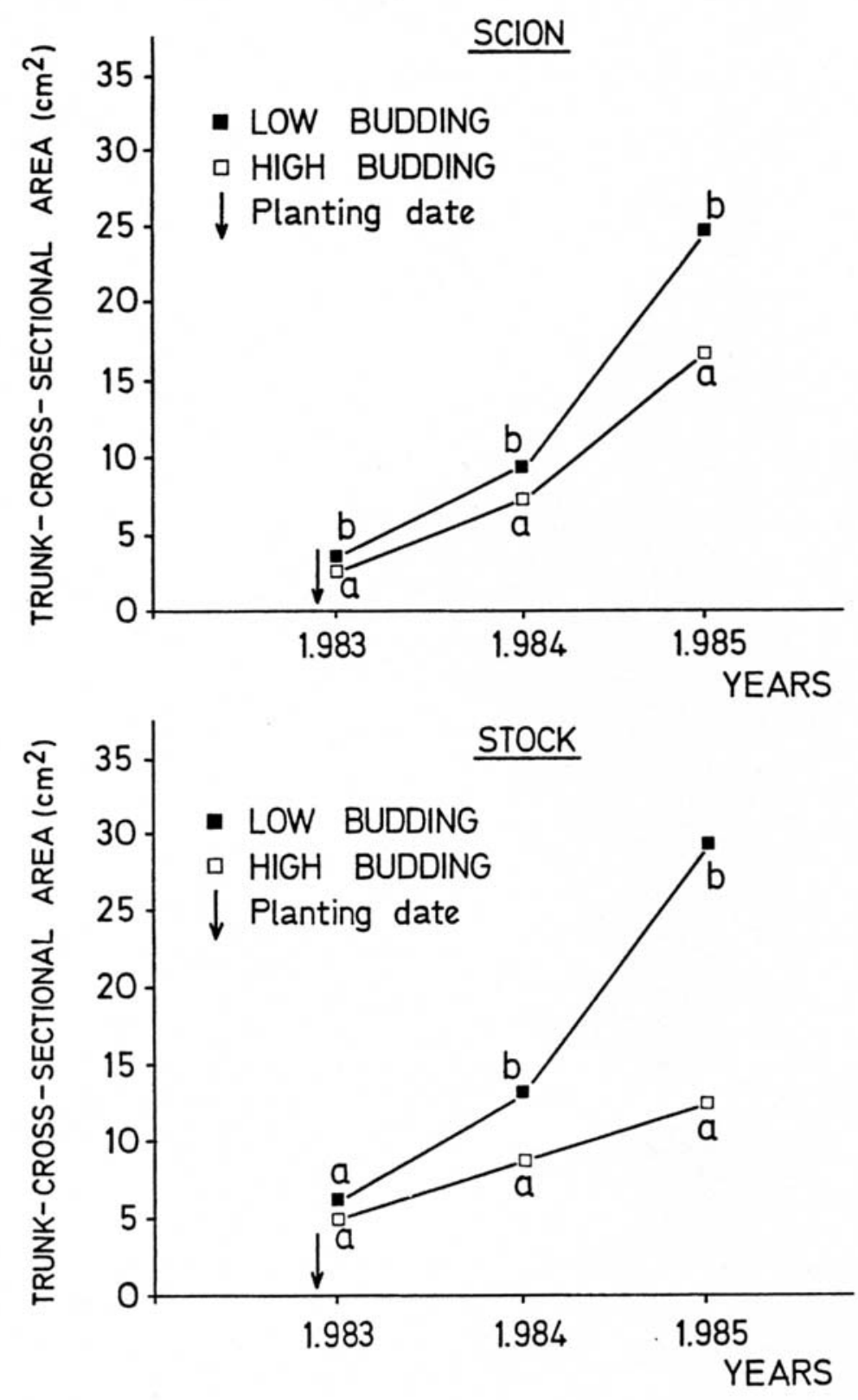

Figure 1. Growth of scion and stock of 'Agua de Aranjuez' pear trees budded on Quince A at different heights. 